\title{
ANALISIS DAN PERANCANGAN SISTEM INFORMASI PADA SMA NEGERI 18 HALMAHERA SELATAN SEBAGAI MEDIA PROMOSI BERBASIS WEB
}

\section{ANALYSIS AND INFORMATION SYSTEM DESIGN IN SMA NEGERI 18 SOUTH HALMAHERA AS MEDIA PROMOTION OF WEB-BASED}

\author{
Rusli Muhidin $^{1}$, N Faisal Kharie ${ }^{2}$, Muin Kubais ${ }^{3}$ \\ Prodi Teknik Komputer \\ Politeknik Sains dan Teknologi Wiratama Maluku Utara \\ rusli_muhidin@yahoo.com
}

\begin{abstract}
Abstrak
Sekolah Menengah Atas (SMA) Negeri 18 Halmahera Selatan merupakan salah satu unit pendidikan yang juga harus mengelola informasi yang memudahkan baik bagi pihak sekolah maupun bagi masyarakat. Berdasarkan pengamatan, sistem pengelolaan informasi SMA Negeri 18 Halmahera Selatan masih bersifat manual, seperti profil sekolah, data siswa, data guru, dan informasi jadwal pelajaran. Dengan sistem yang manual ini menjadikan sekolah sebagai satu-satunya tempat memperoleh informasi. Masyarakat hanya dapat mengetahui keadaan dan infomasi yang menyangkut sekolah dan Kegiatan Belajar Mengajar (KBM) dengan berkunjung langsung kesekolah. Penilitian bertujuan mengetahui masalah sebelum membangun Sistem Informasi pada SMA Negeri 18 Halmahera Selatan Berbasis Web diharapkan dengan adanya sistem ini dapat mempermudah sosialisasi atau mempromosikan sekolah pada masyarakat luas dengan menggunakan website
\end{abstract}

Kata kunci: Analisis, Perancangan Sistem Informasi, Promosi, Website

Abstract

SMA Negeri 18 South Halmahera is one of the education units must also manage the information that makes it easy both for the school and for the community. Based on observation, information management systems SMA Negeri 18 South Halmahera still manual, such as the school profile, student data, teacher data, information and lesson schedule. With a manual system and this made the school as the only place to obtain information. The public can only know the state and information concerning the school and Teaching and Learning Activities with a visit directly to the school. The Research aims to find out the problem before building the Information System in SMA Negeri 18 South Halmahera-Based Website expected with this system can facilitate the dissemination or promoting the school in the wider community by using the website

\section{Keywords: Analysis, Design Information Systems, Promotion, Website}

\section{PENDAHULUAN}

Transformasi kehidupan sosial melalui teknologi informasi semakin menunjukan kemapanannya dengan tingkat efisiensi dan efektifitas kerja yang melampaui cara kerja manual. Berbagai organisasi mulai melakukan perombakan struktural dan kultural guna menunjang kinerja dan pencapaian tujuannya. Pengolahan data secara terkumputerisasi, sosialisasi keadaan sekolah dan penerimaan siswa baru dapat dilakukan melalui koneksi 
website dengan jaringan internet. Urgensi penggunaan teknologi ini tentunya memiliki keunggulan diantaranya akurasi data, kecepatan, ketepatan, efisiensi dan tingkat keamanan apabila dibandingkan dengan sistem manual.

Secara praktis internet memberikan kemudahan bagi masyarakat dalam mengakses berbagai informasi. Komunikasi antara lembaga pendidikan dengan masyarakat luas dapat disalurkan melalui koneksi dunia internet. Sekolah dapat memberikan layanan informasi melalui fitur website sehingga masyarakat yang ingin mendapatkan informasi tidak harus mengunjungi sekolah tersebut, akan tetapi dapat mengakses informasi melalui internet.

Pada era globalisasi seperti sekarang ini, sebuah lembaga pendidikan dituntut harus dapat mengikuti kemajuan teknologi, khususnya pada bidang teknologi informasi. Teknologi informasi yang baik akan memudahkan sebuah lembaga pendidikan untuk memasarkan atau mempromosikan kondisi sekolah kepada para masyarakat umum, sehingga dengan mudah sekolah dapat memenangkan persaingan yang semakin ketat seperti sekarang ini

Kemajuan teknologi informasi, mendorong banyak manusia untuk menciptakan inovasi - inovasi baru untuk membantu manusia dalam mendapatkan informasi dengan cepat dan mudah. Sebuah lembaga pendidikan harus dapat membuat layanan informasi dan promosi dengan baik untuk menarik perhatian masyarakat umum. Disamping informasi yang akurat, cepat, dan mudah, informasi yang disampaikan harus dikemas dengan menarik.

Sekolah Menengah Atas (SMA) Negeri 18 Halmahera Selatan merupakan salah satu unit pendidikan yang terletak di Halmahera Selatan Provinsi Maluku Utara yang dalam mengelola data informasi sekolah untuk memudahkan bagi pihak sekolah maupun bagi pihak masyarakat. Berdasarkan pengamatan, pengelolaan sistem informasi SMA Negeri 18 Halmahera Selatan masih bersifat manual, seperti profil sekolah, data siswa, data guru, dan informasi jadwal pelajaran. Dengan sistem yang manual ini menjadikan sekolah sebagai satu-satunya tempat memperoleh informasi. Masyarakat hanya dapat mengetahui keadaan dan infomasi yang menyangkut sekolah dan Kegiatan Belajar Mengajar (KBM) dengan berkunjung langsung kesekolah.

\section{Rumusan Masalah}

Berdasarkan uraian latar belakang sebelumnya, maka permasalahan penelitian ini adalah Bagaimana Menganalisis dan Merancang Sistem Informasi Pada SMA Negeri 18 Halmahera Selatan Sebagai Media Promosi Berbasis Web?

\section{LANDASAN TEORI \\ Pengertian Informasi}

Menurut Hartono (2013:15). Informasi pada dasarnya adalah himpunan data yang telah di olah menjadi suatu yang memeliki arti dan kegunaan yang lebih luas. Mulyanto (2009:12) informasi adalah data yang telah diolah menjadi bentuk yang lebih berguna bagi yang menerimanya

\section{Pengertian Sistem Informasi}

Menurut Hartono (2013:16) Sistem informasi adalah seperangkat komponen yang saling berhubungan, yang bekerja untuk mengumpulkan dan menyimpan data serta mengolahnya menjadi informasi untuk digunakan. Burch dan Strater 
(2005:15) Kumpun bagian-bagian yang formal dan sistematis yang melaksanakan operasi pengolahan data untuk (a) memenuhi persyartan pengolahan data yang legal dan transaksional, (b) memberikan informasi kepada manajemen untuk mendukung kegiyatan-kegiyatan perencanaan, pengendalian, dan pengambilan keputusan, dan (c) memberikan bermacam-macam laporan seperti yang diperlukan oleh pihak-pihak luar.

\section{Pengertian Promosi}

Niken Tri Hapsari (2010:12) Promosi merupakan salah satu alat komunikasi antara penjual dan pembeli yang sangat diperlukan dalam kegiatan usaha (bisnis). Dengan berpromosi, penjual dapat menyebarluaskan informasi usaha (bisnis), memengaruhi, atau membujuk pembeli/konsumen, dan juga bisa meningkatkan agar barang/jasa yang kita jual tidak terlupakan dari benak konsumen.

Dengan berpromosi, sebuah usaha semakin dikenal dan diketahui oleh banyak orang. Jika sudah dikenal dan diketahui oleh banyak orang, kemungkinan pembeli barang/jasa yang dijual akan semakin banyak. Jika pembelinya banyak, pasti kesempatan memperoleh keuntungan pun akan semakin terbuka lebar dalam usaha (bisnis) juga akan semakin berkembang menjadi lebih besar.

\section{Pengertian XAMPP}

Nugroho $\quad$ (2008:75) XAMPP merupakan paket $P H P$ yang berbasis Open Source yang dikembangkan oleh sebuah komunitas Open Source. Dengan menggunakan XAMPP tidak perlu lagi bingung untuk melakukan penginstalan program-program yang lain, karena semua kebutuhan telah disediakan oleh XAMPP. Dalam hal ini XAMPP ialah sebuah perangkat lunak program aplikasi (aplication software) yang menyediakan Apache, MySQL, dll. Sebenarnya tanpa aplikasi ini kita juga dapat membuat database $M y S Q L$ dan juga menjalankan PHP pada komputer kita, yaitu dengan cara instal apache dan $M y S Q L$ secara langsung. Tetapi XAMPP menyediakan interface atau tampilan yang memudahkan para pengguna, apalagi bagi para pemula. Tetapi para master web developer sekalipun menggunakan xampp, agar lebih cepat dalam membuat database. Contohnya seperti jika kita ingin membuat database, maka langsung saja akses ke phpmyadmin. Hal ini lebih cepat dan praktis ketimbang membuatnya lewat command prompt.

\section{Pengertian Analisis Sistem}

Analisis sistem merupakan tahapan paling awal dari pengembangan sistem yang menjadi fondasi menentukan keberhasilan sistem informasi yang dihasilkan nantinya. Analis sistem adalah sebuah istilah yang secara kolektif mendeskripsikan fase-fase awal pengembangan awal. Menurut Al Fatta (2001:6) analisa sistem adalah penguraian dari suatu sistem informasi yang utuh ke dalam bagian-bagian komponennya dengan maksud untuk mengidentifikasikan dan mengevaluasi permasalahanpermasalahan yang diharapkan sehingga dapat di usulkan perbaikan-perbaikannya. Analisis sistem secara sistematis menilai bagaimana fungsi dengan cara mengamati proses input dan data proses output informasi untuk membantu peningkatan proses organisasional. Dengan demikian 
analisis sistem mampunyai tiga peranan penting yaitu: 1) Sebagai konsultan, 2) Sebagai ahli pendukung, 3) Sebagai ahli perubahan.

Sejalan dengan pengertian diatas, Taufiq (2013:153), analisis sistem adalah suatu kegiatan mempelajari sistem (baik sistem manual ataupun sistem yang sudah komuterisasi) secara keseluruhan mulai dari menganalisa sistem, analisa masalah, desain logic, dan memberikan keputusan dari hasil analisis tersebut.

\section{Perancangan Sistem}

Tahapan perancangan memeliki tujuan untuk mendesign sistem baru yang dapat menyelesaikan masalah-masalah yang dihadapi perusahan yang diperoleh dari pemilihan alternative sistem yang terbaik. Mengenai hal ini Al Fatta (2007:24) menjelaskan bahwa analisis dan desain sistem informasi merupakan organisasional kompleks dimana sistem informasi berbasis komputer diimplementasikan. Sedangkan Menurut Jogiyanto (dalam Taufiq, 2013:168)

\section{METODE PENELITIAN}

Menurut Sugiyono (2012), pengumpulan data dalam penelitian dilakukan melalui tiga kegiatan, yaitu observasi, wawancara dan dokumentasi. Namun dalam penelitian ini hanya menggunakan dua dari tiga kegiatan di atas.

a. Observasi, yaitu merupakan pengumpulan data dengan mengamati lansung sebuah fenomena yang terjadi dilapangan, mengamati tidak hanya meneliti, melainkan juga merekam, menghitung dan mencatat kejadian.

b. Wawancara adalah proses pengumpulan data dengan cara tanya jawab langsung dengan pimpinan dan staf SMA Negeri 18 Halmahera

Selatan tentang kondisi sekolah.

\section{Metode Analisis Kelemahan Sistem}

Menurut Al fatta (2007:51) untuk menentukan suatu sistem baru itu layak atau tidak, maka diperlukan suatu analisis terhadap kriteria-kriteria yaitu kinerja (Performance), informasi (Information), ekonomi (Economic), kontrol (Control), efisiensi (Efficiency), dan pelayanan (Services) yang lebih dikenal sebagai Analisis PIECES, dengan analisis ini kita bisa mendapatkan beberapa masalah dan akhirnya dapat memecahkan masalah utamanya.

\section{Analisis Kinerja (Performance)}

Masalah pada kinerja terjadi ketika tugas-tugas bisnis dijalankan terlalu lambat dalam mencapai sasaran. Kinerja pada system lama tidak efektif dan membutuhkan waktu banyak untuk membuat dan mengelola suatu data menjadi informasi. Misalnya dalam pembuatan dan pendistribusian brosurbrosur dan spanduk.

\section{Analisis Informasi (Information)}

Informasi adalah salah satu faktor yang penting, sebab informasi merupakan titik awal untuk mengoreksi keadaan dalam organisasi. Kemampuan sistem informasi berbasis web dalam menghasilkan informasi yang bermanfaat bisa diandalkan. Untuk menciptakan peluang dalam menyukseskan kegiatankegiatan siswa pada SMA Negeri 18 Halmahera Selatan, masih terdapat informasi yang kurang optimal.

\section{Analisis Ekonomi (Economic)}

Berdasarkan penilaian secara ekonomi, dapat dilihat bahwa sistem lama 
membutuhkan biaya operasional yang tidak sedikit. Apalagi ketika terjadi kesalahan dalam input data, yang pasti biaya operasional bertambah lagi. Dalam sistem yang baru juga membutuhkan biaya yaitu pengadaan domain dan hosting tetapi hanya satu tahun sekali, tetapi manfaat yang didapat jauh lebih optimal dengan media komputer dan internet.

\section{Analisis Pengendalian (Control)}

Kontrol digunakan untuk meningkatkan kinerja sistem, mendeteksi penyalahgunaan sistem dan menjamin keamanan data dari pihak luar yang tidak berkepentingan serta menjamin keamanan data dan informasi yang dihasilkan, dan dengan adanya control maka tugas maupun kinerja yang mengalami gangguan bisa diperbaiki. Pengendalian terhadap sistem yang berjalan menunjukan seberapa jauh sistem ini di dalam melakukan suatu kegiatan semakin sedikit melakukan kesalahan yang dilakukan dalam suatu kegiatan maka tingkat pengendalian sistem semakin baik.

\section{Analisis Efisiensi (Efficiency)}

Efisiensi berhubungan dengan bagaimana sumber daya yang ada dapat digunakan dengan sebaik mungkin dengan pemborosan yang paling minimum. Sistem lama masih kurang efisien karena kebutuhan informasi bagi pengguna tidak diperoleh dengan cepat dan akurat karena adanya keterbatasan ruang dan waktu dalam memperoleh informasi yang ada pada SMA Negeri 18 Halamhera Selatan.

\section{Analisis Pelayanan (Service)}

Peningkatan pelayanan pada SMA Negeri 18 Halmaera Selatan berguna untuk memberikan informasi yang lebih baik bagi pimpinan serta meningkatkan kepuasan bagi siswa dan masyarakat luas. Pelayanan yang dilakukan pada pihak SMA Negeri 18 Halmaera Selatan masih memakai sistem yang bersifat manual.

\section{Analisis Sistem Yang Berjalan}

Sistem yang sedang berjalan di SMA Negeri 18 Halmahera Selatan, terbagi menjadi dua bagian yaitu staf administrasi dan staf kurikulum. Pada bagian staf administrasi proses pengimputan data hanya mencakup pada bagian profil sekolah, data guru, data siswa, dan lainlain. Selanjutnya data-data tersebut disimpan dalam file dokumen sekolah. Sedangkan staf kurukulum hanya bisa mengimput data maupun memproses data berupa jadwal kegiatan belajar mengajar. Selanjutnya jadwa kegiatan belajar disampaikan melalui papan informasi.

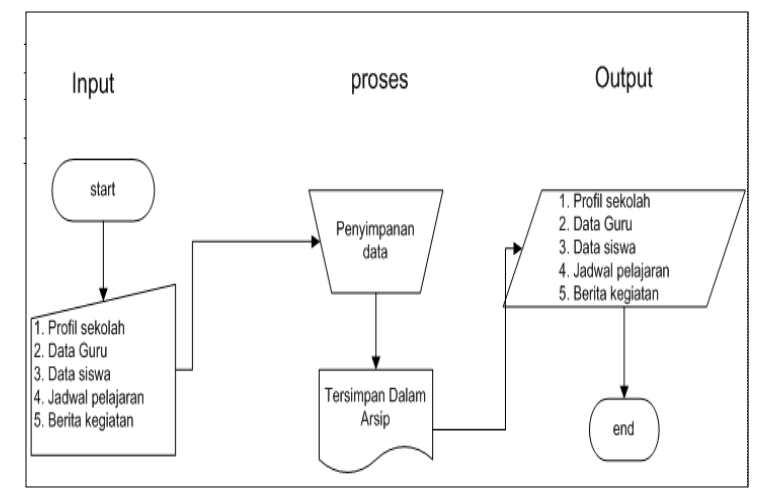

Gambar 1: Sistem Yang Berjalan

\section{Analisis Sistem yang Diusulkan}

Untuk mengatasi berbagai permasalahan yang terdapat pada sistem yang berjalan, maka pada bagian ini dikembangkan sistem berbasis web. Adapun sistem yang diusulkan dapat dilihat pada gambar berikut. 


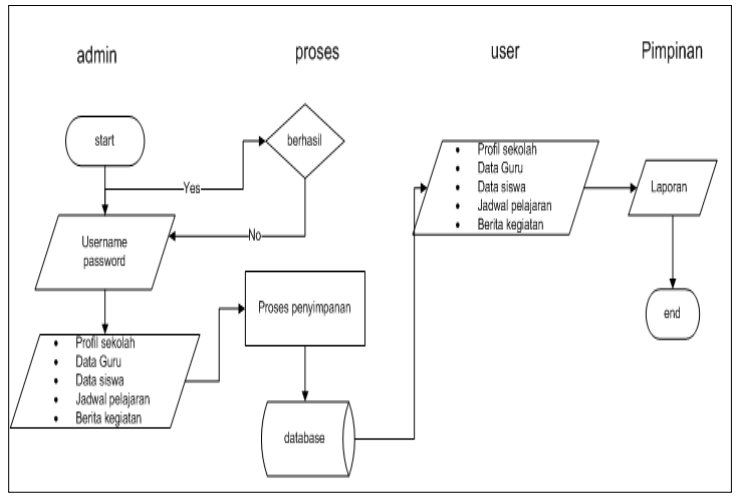

Gambar 2: Sistem yang Diusulkan

\section{Analsis Kebutuhan Sistem}

\section{Kebutuhan Fungsional}

Dari hasil analisis kebutuhan fungsional dibutuhkan suatu sistem informasi yang bermanfaat bagi guru, siswa dan pengunjung yaitu media informasi berbasis website. Dimana informasi yang disajikan dapat diakses dengan menggunakan media internet dan admin dapat manajemen database pada sistem.

\section{Kebutuhan Non-Fungsional}

Kebutuhan Non-Fungsional merupakan kebutuhan perangkatperangkat yang mendukung dalam pembuatan sistem informasi di antaranya:

1. Perangkat Keras (Hardware)

Untuk merancang dan membuat media informasi berbasis web dibutuhkan perangkat keras agar program aplikasi yang dibuat dapat berjalan dengan baik. Spesifikasi yang digunakan adalah computer PC dimana spesifikasinya sebagai berikut

a. Intel Pentium Processor Dual Core J2900 (2.41 GHz, 2M cache)

b. Mainboard Intel ${ }^{\circledR}$ Xeon ${ }^{\circledR} 3200$ / 3000 Series, Core ${ }^{\mathrm{TM}} 2$ Quad / Duo / Extreme Series

c. Monitor LCD LG 15.6 Inch P166HQL LED Size 15 Inch

d. RAM DDR3 V-Gen 2 Gb PC e. Hard Disk Hardisk Internal Seagate $500 \mathrm{~Gb}$ SATA

f. Mouse, keyboard, UPS dan printer

2. Perangkat lunak (Software)

Software atau perangkat lunak yang digunakan untuk mendukung dan merancang pembuatan media informasi berbasis web harus sesuai dengan kebutuhan. Perangkat lunak yang digunakan adalah sebagai berikut:

a. Sistem operasi windows 7 ultimate

b. Notepad++ untuk editing script code

c. Web server XAMPP (Apache, MySQL)

d. Microsoft Office Word membuat laporan

e. Microsoft Visio untuk desain sistem

f. Mozilla firefox untuk browser dan menjalankan sistem

g. Bahasa pemograman HTML, PHP, SQL, Dan CSS.

3. Kebutuhan Pengguna (User)

Dalam kebutuhan ini Admin memiliki hak penuh dalam mengakses data Berita dan pengumuman, Profil Sekolah, Jadwal Pelajaran, data Guru, data Siswa, data Kegiatan dan Buku Tamu, juga memberikan laporan dari data-data tersebut apabila sewaktuwaktu pimpinan yakni Kepala Sekolah atau Dinas yang bersangkutan dalam membutuhkan data-data tersebut

\section{Analisis Kelayakan Sistem}

Analisis kelayakan sistem adalah suatu analisis yang akan digunakan untuk menentukan kemungkinan apakah pengembangan proyek sistem layak diteruskan atau dihentikan. Dalam hal ini diperlukan pertimbangan ketika menentukan seberapa banyak keuntungan yang di dapat dan biaya yang diperlukan 
dari sistem baru tersebut. Adapun beberapa kelayakan yang perlu dipertimbangkan antara lain

\section{Kelayakan Operasional (Operational Feasibility)}

Dijelaskan pada kelayakan teknis diatas, untuk pengoperasian aplikasi website membutuhkan media computer dan akses internet. Karena SMA Negeri 18 Halmaera Selatan telah mempunyai keduanya, maka dari segi kelayakan operasional website ini layak digunakan. Namun demikian, agar dapat berjalan lebih optimal maka personil akan menangani sistem yang akan diterapkan, diperlukan pelatihan untuk menambah kemampuan dasar untuk mengoperasikan sistem yang akan diterapkan tersebut

\section{Kelayakan Ekonomi}

Kelayakan ekonomi pada penerapan dan pengembangan suatu sistem menyangkut tentang pengadaan yaitu besarnya dana yang harus dikeluarkan dengan harapan manfaat yang lebih besar yaitu akan diperoleh dari pengembangan sistem tersebut.

a. Biaya

Komponen biaya dalam hal ini adalah biaya yang berhubungan dengan pengembangan sistem yang dapat diklasifikasikan ke dalam 4 kategori yaitu sebagai berikut: Biaya pengadaan, Biaya persiapan operasional, Biaya proyek, Biaya operasional dan perawatan

b. Manfaat

Komponen ini dapat diklarifikasikan ke dalam dua bentuk keuntungan, yaitu: Keuntungan berwujud (Tangible Benefits) Keuntungan yang berupa penghematan peningkatan di dalam organisasi dalam bentuk satuan nilai uang dan Keuntungan tidak berwujud (Intangible Benefits) Keuntungan yang tidak dapat diukur dalam bentuk satuan nilai. Oleh karena itu pengukurannya dilakukan dengan taksiran

Pengembangan suatu sistem informasi merupakan suatu investasi. Investasi berarti dikeluarkannya sumber - sumber daya untuk mendapatkan manfaat dimasa mendatang. Investasi untuk mengembangkan sistem informasi juga membutuhkan sumber-sumber daya. Sebagai hasilnya, sistem informasi yang baru diharapkan akan memberikan manfaat-manfaat yang dapat berupa penghematan - penghematan atau manfaatmanfaat baru. Jika manfaat yang diharapkan lebih kecil dari sumbersumber daya yang dikeluarkan, maka sistem informasi yang baru ini dikatakan tidak bernilai atau tidak layak.

Dalam mengidentifikasi masalah biaya pada SMA Negeri 18 Halmahera Selatan berikut Tabel rincian biaya dan manfaat dalam kegiatan Penelitian yang akan di rencanakan dapat di lihat pada table berikut :

Tabel 1: Rincian Biaya Dan Manfaat

\begin{tabular}{|c|c|c|c|}
\hline KETERANGAN & TAHUN 0 & TAHUN I & TAHUN II \\
\hline \multicolumn{4}{|l|}{$\begin{array}{l}\text { BIAYA-BIAYA } \\
\text { 1. Biaya pengembangan proyek }\end{array}$} \\
\hline \multicolumn{4}{|l|}{ a. biaya tahapan analisis sistem } \\
\hline - biaya pengumpulan data & 200,000 & 0 & 0 \\
\hline - biaya dokumentasi & 100,000 & 0 & 0 \\
\hline Jumlah tahap analisis sistem & 300,000 & 0 & 0 \\
\hline \multicolumn{4}{|l|}{ b. biaya tahap perancangan sistem } \\
\hline - biaya analis & $2,100,000$ & 0 & 0 \\
\hline - biaya programmer & $3,050,000$ & 0 & 0 \\
\hline - biaya pembelian web hosting & 700,000 & 0 & 0 \\
\hline Jumlah tahap perancangan sistem & $5,850,000$ & 0 & 0 \\
\hline \multicolumn{4}{|l|}{ c. biaya tahap penerapan sebelum sistem } \\
\hline - biaya menyusun dan cetak modul & 300,000 & 0 & 0 \\
\hline - biaya pelatihan personil & 500,000 & 0 & 0 \\
\hline Jumlah tahap penerapan sistem & 800,000 & 0 & 0 \\
\hline Total biaya pengembangan proyek & $6,950,000$ & 0 & 0 \\
\hline $\begin{array}{l}\text { 2. Biaya penerapan setelah sistem } \\
\text { berjalan }\end{array}$ & & & \\
\hline a. biaya operasi & & & \\
\hline
\end{tabular}

Volume 2 Nomor 2 | April 2017 


\begin{tabular}{|c|c|c|c|}
\hline - biaya overhead & 0 & 410,000 & 680,000 \\
\hline - biaya pemakaian web hosting & 0 & $4,200,000$ & $4,400,000$ \\
\hline \multicolumn{4}{|l|}{ b. biaya perawatan } \\
\hline -biaya perawatan hardware & 0 & 525,000 & 620,000 \\
\hline Total biaya operasi dan perawatan & & $5,135,000$ & $5,700,000$ \\
\hline Total Biaya -biaya & $6,950,000$ & $5,135,000$ & $5,700,000$ \\
\hline \multicolumn{4}{|l|}{ Manfaat Wujud } \\
\hline \multicolumn{4}{|l|}{ 1. Manfaat berwujud } \\
\hline a. peningkatan jumlah siswa & 0 & $3,250,000$ & $7,100,000$ \\
\hline b. pengurangan biaya iklan/promosi & 0 & 500,000 & $2,400,000$ \\
\hline c. pengurangan biaya transportasi & 0 & $1,000,000$ & $3,250,000$ \\
\hline Total manfaat berwujud & & $4,750,000$ & $12,750,000$ \\
\hline \multicolumn{4}{|l|}{ 2. Manfaat tak berwujud } \\
\hline a. perbaikan pelayanan siswa & 0 & $2,000,000$ & $2,500,000$ \\
\hline b. peningkatan citra sekolah & 0 & $1,900,000$ & $3,550,000$ \\
\hline \multirow[t]{2}{*}{ Total manfaat tak berwujud } & $\mathbf{0}$ & $3,900,000$ & $6,050,000$ \\
\hline & $\mathbf{0}$ & $8,650,000$ & $18,800,000$ \\
\hline Selisih Total Biaya Dan Manfa & $6,950,000$ & $3, \mathbf{5 1 5 , 0 0 0}$ & $13,100,000$ \\
\hline
\end{tabular}

\section{Kelayakan Teknologi}

Kelayakan teknologi berhubungan dengan penerapan media internet pada teknologi yang ada. dari segi hardware, SMA Negeri 18 Halmahera Selatan sudah memiliki laboratorium Komputer. Ketersediaan web hosting dan domain name di internet sangat banyak dengan harga yang bervariasi. Menjadi kemudahan dalam pelaksanaan program ini.

\section{Kelayakan Hukum}

Kelayakan hukum dimaksudkan untuk mengetahui apakah sistem yang akan diterapkan melanggar hukum atau tidak. Misalnya kelayakan dalam hal legalitas software. Dalam hal ini software yang digunakan dalam pembuatan sistem informasi pada SMA Negeri 18 adalah Software Open Source yang bersifat free, sehingga sangat layak. Selain itu isi dari situs ini tidak memuat hal-hal yang melanggar hukum seperti pornografi, SARA, dan lain-lain.

\section{Kelayakan Sumber Daya Manusia}

Dalam teknologi komputer yang digunakan sekarang ini membutuhkan Sumber daya Manusia yang mendukung, dimana tingkat pendidikan pegawai dan guru pada SMA Negeri 18 Halmahera Selatan sangat beragam dalam penguasaan teknologi informasi, serta ketrampilan yang dimiliki oleh para pegawai dan guru dapat dipakai secara optimal untuk mengelola Sistem Informasi ini.

\section{PERANCANGAN SISTEM}

\section{Diagram Konteks}

Context Diagram digunakan untuk menggambarkan proses kerja sistem secara umum. Context Diagram berupa Data Flow Diagram yang menggambarkan garis besar operasional sistem. Context Diagram Sistem Informasi SMA Negeri 18 Halmahera Selatan dapat dilihat pada gambar berikut :

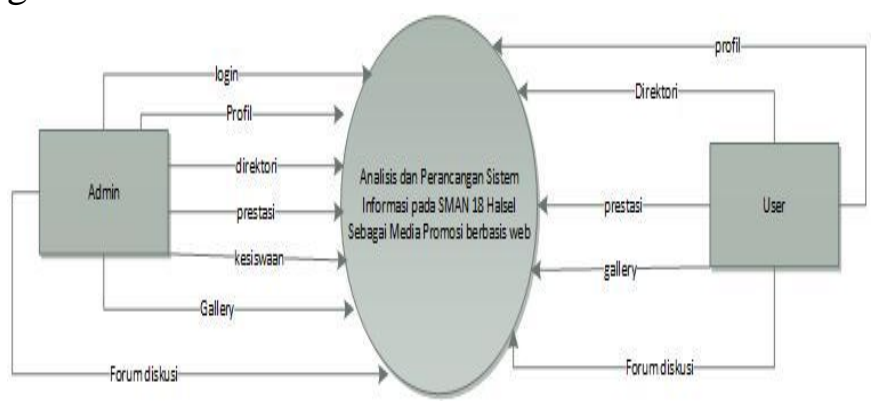

Gambar 3: Diagram Konteks

\section{Diagram Flow Data (DFD Level 1 Proses)}

Data Flow Diagram (DFD) digunakan untuk menganalisa sistem yang telah ada atau sistem baru yang akan dikembangkan secara logika tanpa mempertimbangkan lingkungan fisik dimana data tersebut mengalir atau lingkungan fisik dimana data tersebut disimpan. Berikut ini adalah DFD yang akan digunakan dalam proses pembuatan Sistem Informasi SMA Negeri 18 Halmahera Selatan, Berikut adalah 
gambar Diagram Flow Data Level 1 Proses sebagai berikut:

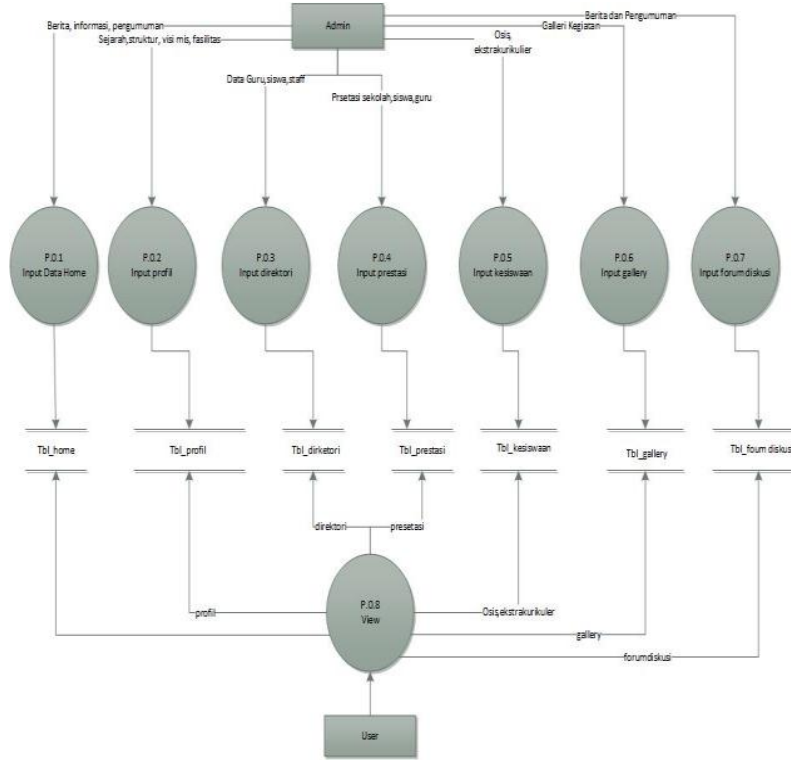

Gambar 4: Diagram Flow Data Level 1

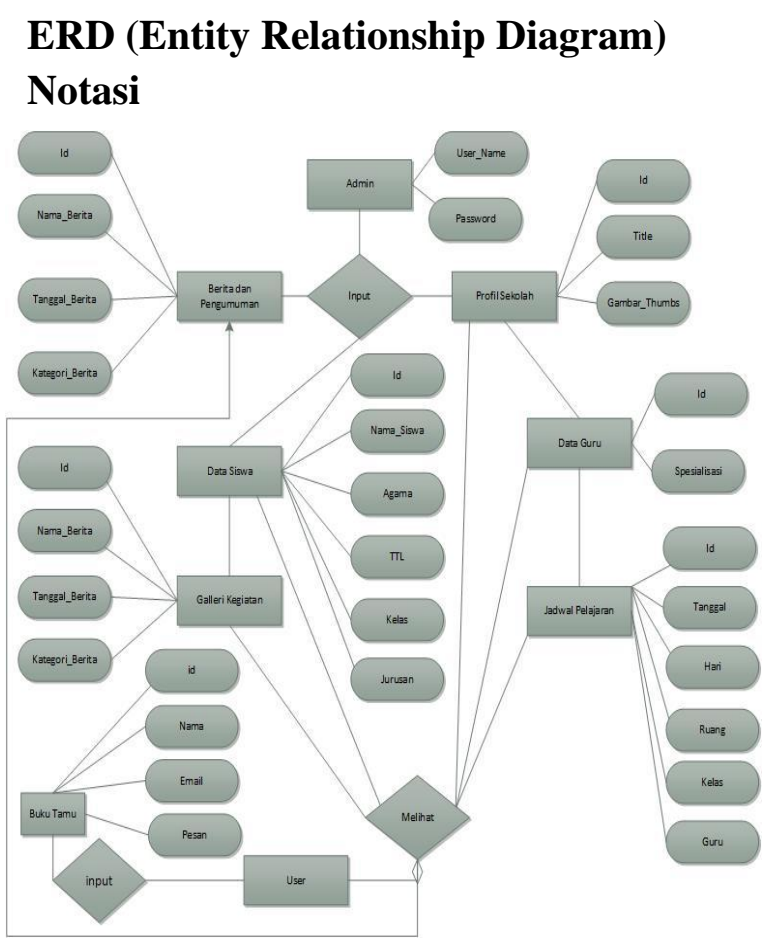

Gambar 5: Entity Relationship Diagram Notasi

\section{ERD (Entity Relationship Diagram)}

Relasi

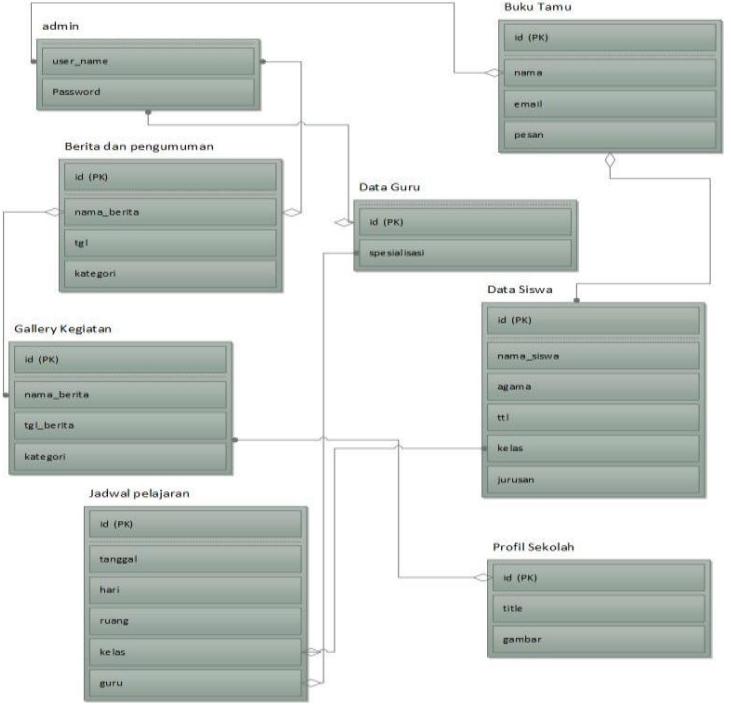

Gambar 6: Entity Relationship Diagram Relasi

\section{Struktur Menu Sistem}

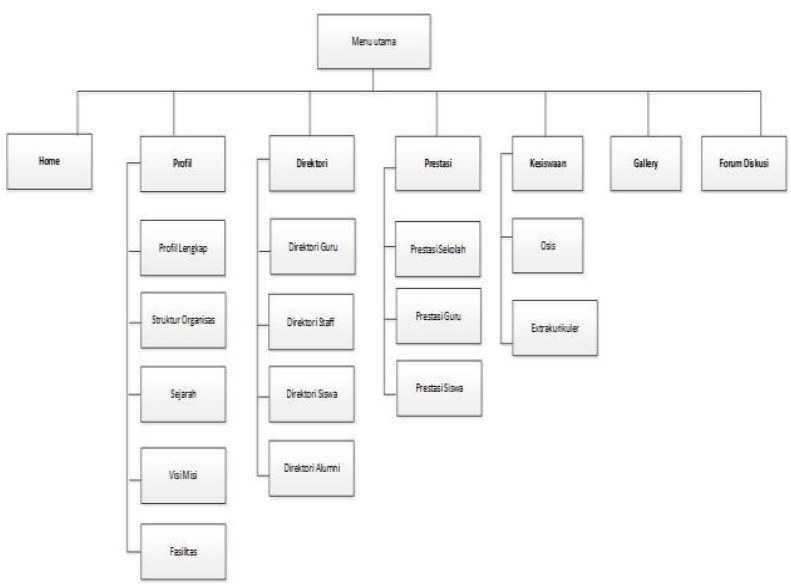

Gambar 7: Struktur menu Sistem

\section{Tampilan Layout Menu Utama}

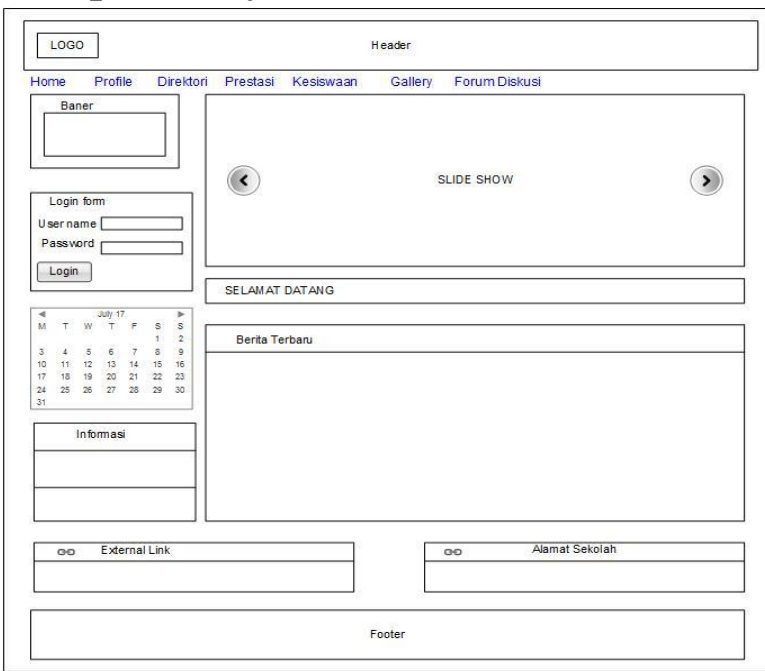

Gambar 8: layout Menu Utama 


\section{Rancangan Struktur Tabel Sistem}

Tabel: 2 Admin

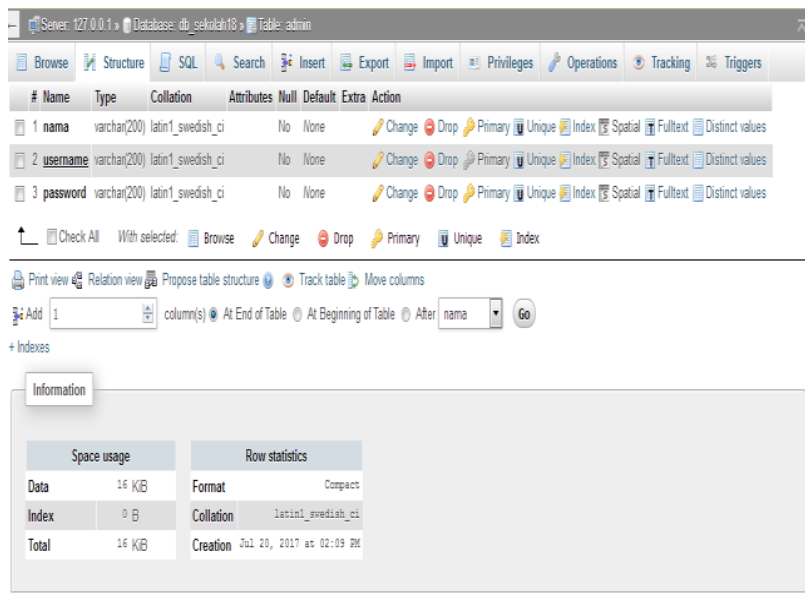

Tabel 3: Data Content

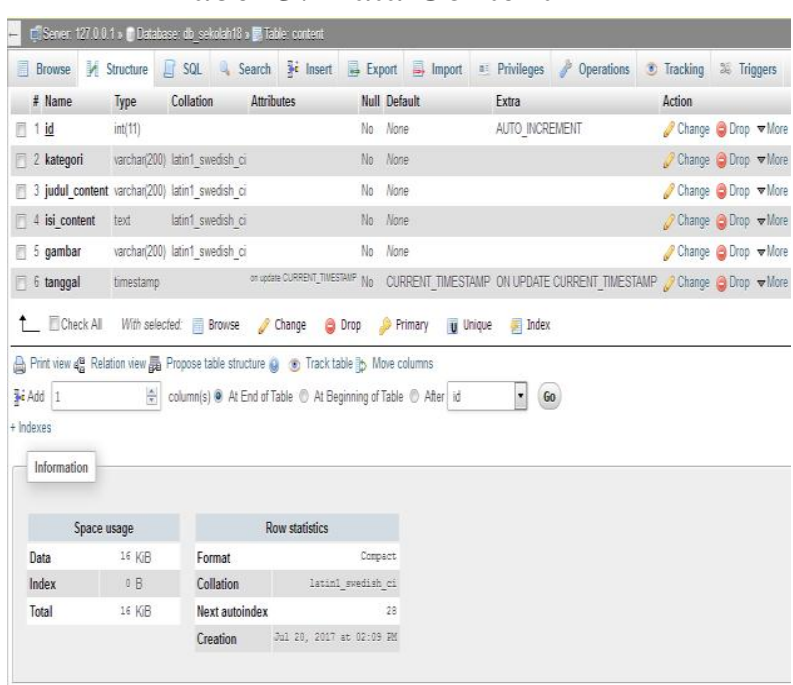

Tabel 4: Direktori

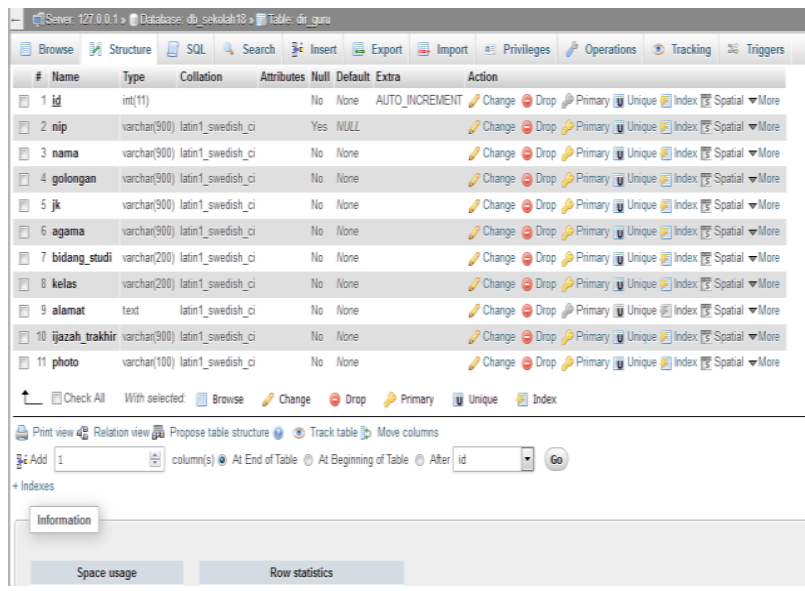

Tabel 5: Halaman

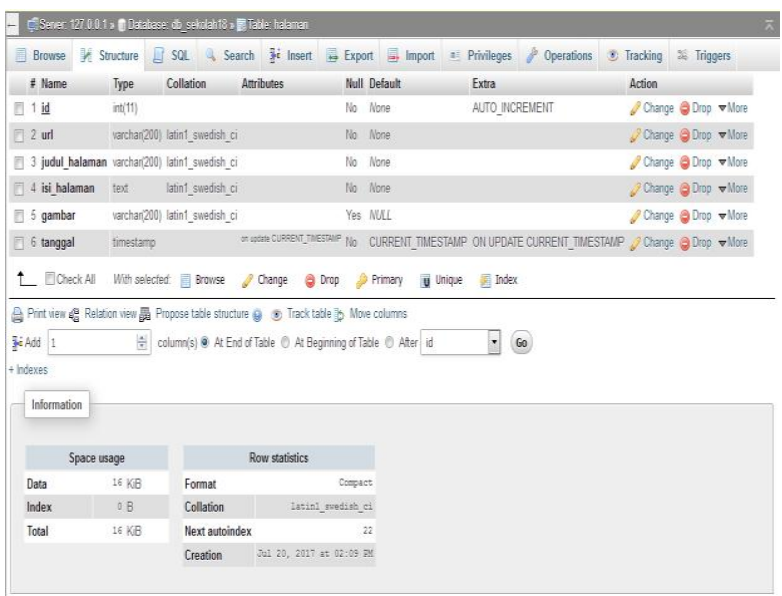

Tabel 6: Tabel Informasi

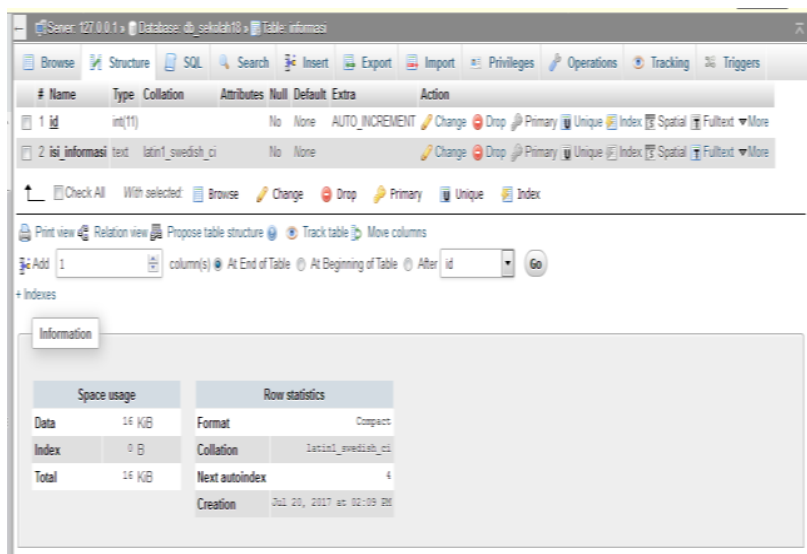

Tabel 7: Gallery

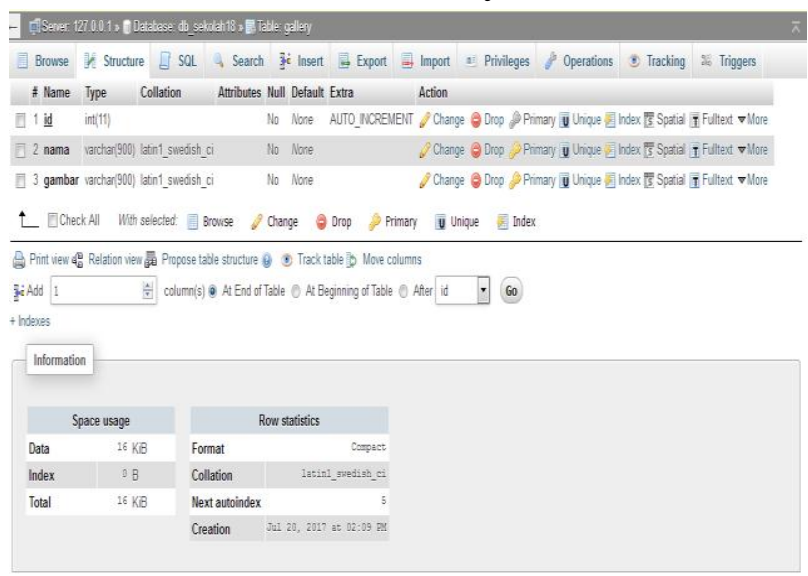

\section{IMPLEMENTASI SISTEM}

Implementasi merupakan tahap meletakan sistem yang sudah dibuat dalam Website dan Database Sistem sesuai dengan rencana yang ditentukan, berikut 
merupakan hasil implementasi Sistem yang sudah di buat

\section{Tampilan Form Login}

\begin{tabular}{l}
$\rightarrow$ Login Form \\
Username \\
Username \\
Password \\
Password \\
Log In \\
\hline
\end{tabular}

Gambar 8: Form Login

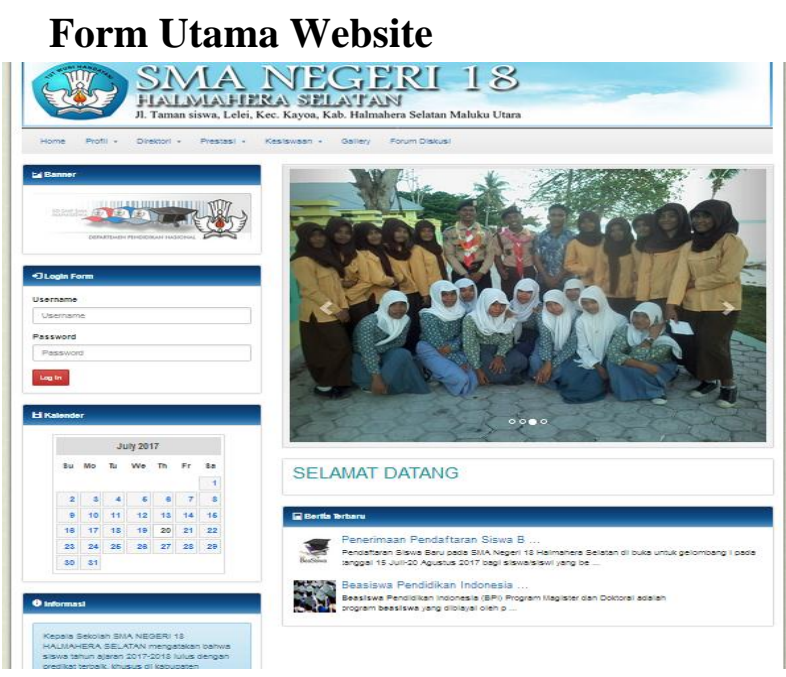

Gambar 9: Form Utama Website

\section{Form Utama Admin}

Dashboard

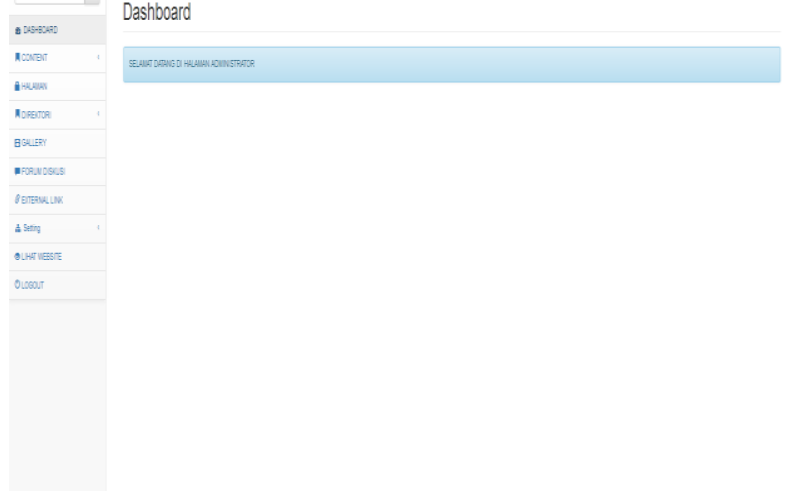

Gambar 10: Form Utama Admin

\section{Form Data Content}

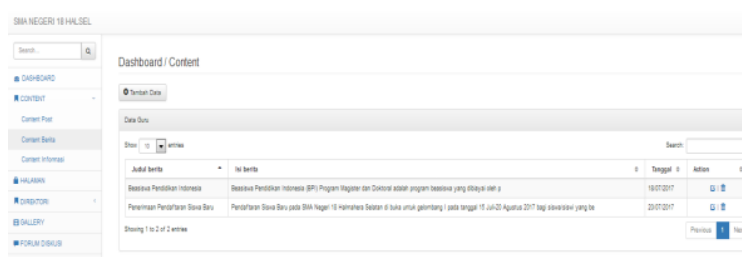

Gambar 11: Form Data Content

\section{Form Direktory Guru}

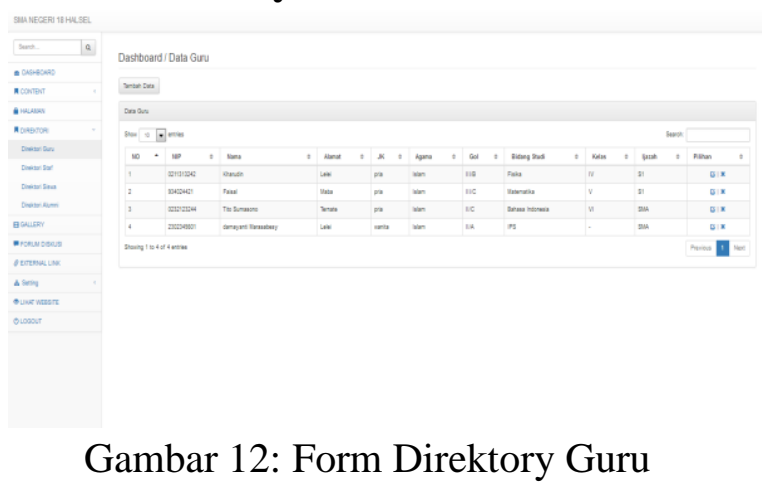

\section{Form Data Halaman}

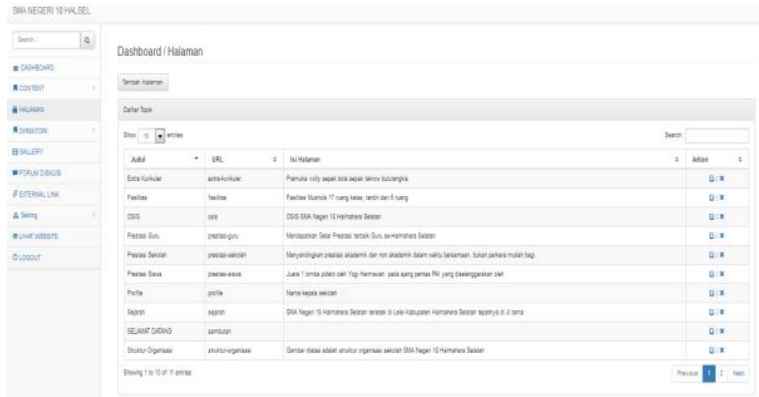

Gambar 13: Form Data Halaman

\section{Form Data Gallery}

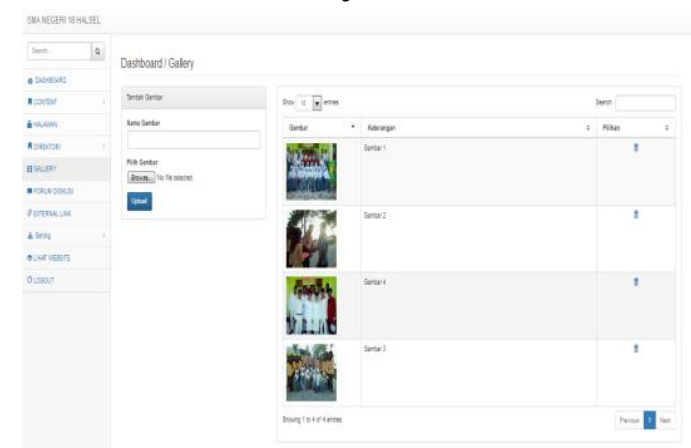

Gambar 14: Form Data Gallery 


\section{Pengujian Sistem}

Pengujian sistem merupakan tahap dimana sistem yang sudah diimplementasi akan diuji pada menu-menu dan komponen sistem yang sudah dibuat dan di terapkan untuk mengetahui proses keberlangsungan yang terjadi pada agar sistem dapat berjalan dengan baik. Metode yang digunakan dalam pengujian sistem adalah Pengujian Blackbox, berikut merupakan tabel blackbox pengujian sistem:

Tabel 8: Uji coba Blackbox Menu Sistem

\begin{tabular}{|c|c|c|c|}
\hline No & Nama Modul & $\begin{array}{l}\text { Jenis Unit Yang di } \\
\text { Uji }\end{array}$ & $\begin{array}{l}\text { Hasil } \\
\text { Test }\end{array}$ \\
\hline \multirow[t]{2}{*}{1} & \multirow{2}{*}{$\begin{array}{l}\text { Form menu } \\
\text { Login }\end{array}$} & Username & Sukses \\
\hline & & Password & Sukses \\
\hline \multirow[t]{7}{*}{2} & \multirow[t]{7}{*}{ Menu Utama } & Home & Sukses \\
\hline & & Profil & Sukses \\
\hline & & Direktory & Sukses \\
\hline & & Prestasi & Sukses \\
\hline & & Kesiswaan & Sukses \\
\hline & & Gallery & Sukses \\
\hline & & Forum Diskusi & Sukses \\
\hline \multirow[t]{5}{*}{3} & \multirow[t]{5}{*}{ Profil } & Profil_lengkap & Sukses \\
\hline & & Struktur_organisasi & Sukses \\
\hline & & Sejarah & Sukses \\
\hline & & Visi_Misi & Sukses \\
\hline & & Fasilitas & Sukses \\
\hline \multirow[t]{4}{*}{4} & \multirow[t]{4}{*}{ Direktori } & Guru & Sukses \\
\hline & & Siswa & Sukses \\
\hline & & Staf & Sukses \\
\hline & & Alumni & Sukses \\
\hline \multirow[t]{3}{*}{5} & \multirow[t]{3}{*}{ Prestasi } & Prestasi_sekolah & Sukses \\
\hline & & Prestasi_guru & Sukses \\
\hline & & Prestasi_Siswa & Sukses \\
\hline \multirow[t]{2}{*}{6} & \multirow[t]{2}{*}{ Kesiswaan } & Osis & Sukses \\
\hline & & Ekstrakurikuler & Sukses \\
\hline 7 & Gallery & Data_gallery & Sukses \\
\hline 8 & Forum_Diskusi & Data_forum diskusi & Sukses \\
\hline
\end{tabular}

\section{KESIMPULAN}

Berdasarkan pembahasan yang ada pada halaman sebelumnya dengan adanya penelitian pada SMA Negeri 18 Halmahera Selatan dengan judul Penilitan "Analisis Dan Perancangan Sistem Informasi Berbasis Website SMA Negeri 18 Halmahera Selatan Menggunakan Php
Dan MySQL“, maka dapat diambil kesimpulan sebagai berikut: 1). Dengan adanya website tersebut maka akan sangat memudahkan bagi masyarakat atau user yang mengakses internet untuk dapat mengetahui tentang sekolah sehingga user akan lebih jelas apabila ingin mendaftarkan diri di SMA Negeri 18 Halmahera Selatan. 2). Dengan adanya website tersebut masyarakat juga dapat dengan mudah mengetahui gambaran umum tentang sekolah, fasilitas dan guru atau karyawan dengan lebih jelas, dan berbagai macam berita tentang sekolah.

Berdasarkan kesimpulan pada penelitian "Analisis Dan Perancangan Sistem Informasi Berbasis Website SMA Negeri 18 Halmahera Selatan“, maka dapat diberikan saran untuk pengembangan sebagai berikut: 1). Diharapkan agar pihak sekolah dapat menerapkan sistem ini dalam mengenalkan informasi sekolah tersebut. 2). Perlu adanya pelatihan kepada admin atau operator dalam mengelola sistem ini agar lebih maksimal

\section{DAFTAR PUSTAKA}

Nugroho, Adi. 2002. Analisis dan Perancangan Sistem Informasi dengan Metodologi Berorientasi Objek. Bandung: Informatika Bandung

Pressman dan Roger S (2002). Rekayasa Perangkat Lunak Pendekatan Praktisi (Buku Satu). Yogyakarta: Andi

Jogiyanto, Hartono, 2005. Analisis \& Desain Sistem Informasi Pendekatan Terstruktur Teori dan Praktek Aplikasi Bisnis. Andi Yogyakarta.

Bunafit Nugroho (2008). Aplikasi Pemrograman Web Dinamis dengan PHP dan Mysql. Yogyakarta: Gava Media 
Agus Mulyanto. 2009. Sistem Informasi

Konsep dan Aplikasi. Pustaka Pelajar. Yogyakarta

Ragil, Wukil 2010, Pedoman Sosialisasi Prosedur Standar. Jakarta: Mitra Wacana Media

Trihapsari, Niken. (2010). Seluk-Beluk Promosi Dan Bisnis, Yogyakarta: A Plus Books

Al-Fatah, Hanif. 2007. Analisis \& Perancangan Sistem Informasi untuk keunggulan bersaing perusahaan \& organisasi modern. Yogyakarta, Andi.

Sugiyono. 2012. Memahami Penelitian Kualitatif. Penerbit CV. Alfabeta: Bandung

Taufiq (2013). Sistem Informasi Manajemen Konsep Dasar, Analisis dan Metode Pengembangan. Graha Ilmu, Yogyakarta

Abdul Kadir (2013). Pengertian MySQL. Tersedia dalam: Buku Pintar Programer Pemula PHP. Yogyakarta. Mediakom.

Hartono, Bambang. 2013. Sistem Informasi Manajemen Berbasis Komputer. Jakarta: Rineka Cipta

Sugiyono. 2015. Metode Penelitian Pendidikan (Pendekatan Kuantitatif, Kualitatif dan $R \& D)$. Penerbit CV. Alfabeta: Bandung.

Muharto, Arisandy Ambarita (2016), Metode Penilitian Sistem Informasi, Deepublish. Yogyakarta

Widayanti, N.A. 2011. Evaluasi Implementasi Sistem Electronic Health Record (EHR) di Rumah Sakit Akademik Universitas Gadjah Mada berdasarkan Metode Analisis PIECES. Tugas Akhir. Yogyakarta: Universitas Gadjah Mada

Tedi Kurnia, Dini Destiani Asep Deddy Supriatna, Perancangan Sistem
Informasi Akademik Nilai Siswa Berbasis Web (Studi Kasus: SMK Ciledug Al-Musaddadiyah Garut), Jurnal Algoritma Sekolah Tinggi Teknologi Garut (STT-Garut), ISSN: 2302-7339 Vol. 09 No. 172012

Saragih, H. 2012. Analysis Information System of Inpatient Billing System's Support for Consumables Logistic Using PIECES Framework: Case Study Promedika Hospital. Journal of Information Systems, Volume 8, Issue 1, April 2012.

Agisa Rusaldi Wildan. (27 Agustus 2016) White Box Testing \& Black Box Testing, [online], 2013, http:// bangwildan.web.id/berita-176-whitebox-testing-black-box-testing.html

Rahmat Sanjaya, Pembuatan Website Profil Dinas Kelautan Dan Perikanan Kabupaten Pacitan, IJNS Indonesian Journal on Networking and Security - Volume 4 No 3 - 2015, ISSN: 2302-5700 (Print) 2354-6654 (Online)

Ilham Ishak, Nuratni S Simin, Sistem Informasi Profil Berbasis Web Sebagai Media Promosi Pada Waterboom Kota Ternate, IJISIndonesian Journal On Information System, Volume 1 Nomor 1 April Tahun 2016

Arisandy Ambarita, Analisis Pengembangan Sistem Informasi Pengolahan Aset Dearah (Studi Kasus: Dinas Pendapatan dan Pengelolaan Aset Daerah Provinsi Maluku Utara), Indonesian Journal on Networking and Security - Volume 5 No 4 Oktober 2016, ISSN: 2302-5700 (Print) 2354-6654 (Online) 